\title{
Involvement of Oxidative Stress, Inflammation, and Glutamate in Ototoxicity, and their Attenuation by Simultaneous Activation of Nrf2 and Elevation of Antioxidant Compounds
}

\author{
Kedar N Prasad \\ Engage Global, 245 El Faisan Drive, San Rafael, CA, USA
}

*Corresponding author: Kedar N Prasad, PhD, Engage Global, 245 El Faisan Drive, San Rafael CA 94903, USA, Tel: 415686-6251

\begin{abstract}
Diverse groups of ototoxic agents and gene mutation induce hearing disorders. Several studies showed that increased oxidative stress, inflammation, and glutamate are involved in the initiation and progression of hearing disorders. Therefore, reducing these biochemical defects before and after exposure to ototoxic agents may prevent and improve the management of hearing loss. Previous studies with a single agent have yielded variable benefits in hearing disorders. This review briefly presents evidence for the involvement of oxidative stress, inflammation, and glutamate in the initiation and progression of hearing disorders. It proposes a novel concept that simultaneous elevation of the levels of antioxidant enzymes, dietary and endogenous antioxidant compounds, and reduction in the levels of glutamate may be necessary for the optimal benefits in prevention and improved management of hearing disorders. Supplementation with micronutrients can elevate the levels of antioxidant compounds and reduce the levels of glutamate. However, increasing the levels of antioxidant enzymes is complex requiring an activation of the nuclear transcriptional factor-2 (Nrf2). This review briefly describes the regulation of activation of $\mathrm{Nrf2}$, and proposes a micronutrient mixture that can simultaneously activate Nrf2, enhance the dietary and endogenous antioxidant compounds levels, and inhibit the release and toxicity of glutamate for prevention and improved management of hearing loss.
\end{abstract}

\section{Keywords}

Oxidative stress, Inflammation, Nuclear transcriptional factor-2 (Nrf2), Hearing disorders, Glutamate

\section{Introduction}

Hearing disorders are caused by diverse groups of ototoxic agents, such as chronic and intense noise, vi- brations, gentamicin, ionizing radiation, cisplatin, large doses of aspirin, bacterial and viral infection, gene mutations, and advanced age. In addition, health conditions, such as ear canal obstruction, mechanical damage to the tympanic membrane, and ossicles of the middle ear and inner ear also contribute to the hearing loss. Approximately 48 million Americans have varying degrees of hearing loss. Among individuals of 65 years of age, one of every three people suffers from this disease. Among children, congenital hearing loss is a major hearing disorder that is estimated to be 2-3 cases per 1000 (Hearing Loss Association of America, 2015). Congenital hearing defects could be primarily due to cytomegalovirus infection during pregnancy or gene mutation. Troops in combat zones, musicians or industrial workers are likely to develop varying degrees of hearing loss despite the use of earplugs. Thus, hearing problems represent a major health concern both for the civilian and military in the USA.

Except for ear protective devices, there are no preventive strategies for reducing the risk of noise-induced hearing loss (NIHL). However, despite the use of earplugs, the energy generated from the noise can penetrate the inner ear damaging the hair cells. In order to develop an effective preventive strategy, the major cellular defects that initiate and promote hearing loss should be identified. Several studies of the past decades indicate that increased oxidative stress [1-6], inflammation [7-13], and glutamate [14-16] play a central role in the initiation and progression of hearing defects. Therefore, reducing these biochemical defects simultaneously may be one of the rational strategies for the

Citation: Prasad KN (2019) Involvement of Oxidative Stress, Inflammation, and Glutamate in Ototoxicity, and their Attenuation by Simultaneous Activation of Nrf2 and Elevation of Antioxidant Compounds. Int J Neurol Neurother 6:083. doi.org/10.23937/2378-3001/1410083

Accepted: May 18, 2019: Published: May 20, 2019

Copyright: (c) 2019 Prasad KN. This is an open-access article distributed under the terms of the Creative Commons Attribution License, which permits unrestricted use, distribution, and reproduction in any medium, provided the original author and source are credited. 
prevention of hearing loss. Several animal studies [1724] showed that the use of primarily one antioxidant reduced the risk of developing hearing loss by decreasing oxidative stress; however, in a few human studies, the use of one or a mixture of a few antioxidants or steroid produced variable degrees of reduction in hearing loss with or without standard therapy [25-31]. The exact reasons for this discrepancy between animal and human studies are unknown. It is possible that a single antioxidant alone may not be sufficient to simultaneously reduce oxidative stress, inflammation and glutamate in humans exposed to ototoxic agents. In addition, a single antioxidant in a high oxidative environment found in patients with hearing loss is oxidized and then acts as a pro-oxidant rather than as an antioxidant.

The treatment of hearing disorders that includes steroids [32,33], glutamate antagonist [34,35], various types of hearing aids [36-38], and cochlear implants $[39,40]$. Although these treatments produce varying degrees of improvements but they are considered unsatisfactory. One of the reasons could be that none of these treatment modalities simultaneously reduce oxidative stress, chronic inflammation and glutamate levels.

A previous study has proposed that simultaneous elevation of the levels of antioxidant enzymes, and dietary and endogenous antioxidant compounds may be necessary for optimally reducing oxidative stress, inflammation and glutamate levels in humans [41]. Supplementation with micronutrients can increase the levels of antioxidant compounds and reduce the levels of glutamate; however, elevating the levels of endogenous antioxidant enzymes is complex that generally requires an activation of the nuclear transcriptional factor-2 (Nrf2).

This review briefly presents evidence for the involvement of oxidative stress, inflammation, and glutamate in the initiation and progression of hearing disorders induced by diverse groups of ototoxic agents. This review briefly discusses the regulation of activation of Nrf2, and proposes a mixture of micronutrients that can simultaneously activate Nrf2, enhance the levels of antioxidant compounds, and reduce the levels of glutamate for prevention and improved management of hearing disorders.

\section{Linkage between ROS, inflammation, and gluta- mate}

Low levels of reactive oxygen species (ROS) are essential for driving several biochemical reactions necessary for maintaining the cellular function; however, high levels of ROS override cellular defense mechanisms against oxidative damage, and induce cellular injury including damage to DNA, RNA, lipid, and protein. If cellular damage is not fully repaired, chronic inflammation sets in motion, which releases free radicals, pro-inflammatory cytokines, adhesion molecules and prostaglandins, all of which toxic are to the cells. Oxidative damage to the auditory cells causes release of glutamate. Glutamate at high concentration is toxic to the hair cells. Several studies show that increased oxidative stress, chronic inflammation and glutamate play an important role in the initiation and progression of hearing disorders. These studies are described under separate sections.

\section{Evidence for the Role of Oxidative Stress in Hearing Disorders}

Exposure to high intensity noise decreased the levels of serum total antioxidant capacity and increased the levels of nitric oxide in guinea pigs [42]. Increased nitric oxide levels can form peroxynitrite that damages the hair cells. Impulse noise exposure also enhanced oxidative stress in some animal studies. The levels of nitric oxide, peroxynitrite, oxidative stress, nuclear factor-kappa-beta (NF-kB), glutamate receptor ( $\mathrm{N}$-methyl-D-aspartate), and calcium are elevated in patients with tinnitus [1-3,43-46]. Noise exposure induced approximately 21 to $42 \%$ of tinnitus in humans $[4,47,48]$. About $34 \%$ of tinnitus patients had post-traumatic stress disorders (PTSDs) [49]. These studies suggested that some common biochemical defects that cause both tinnitus and PTSD might exist in these diseases. Indeed, a recent review has shown that increased oxidative stress occurs in patients with PTSD and tinnitus [50].

NADPH (nicotinamide adenine dinucleotide) oxidases (NOXs) transport electron across the plasma membrane and produce superoxide radicals from oxygen. Exposure to moderate or intense noise increased NOXs activities in the cochlea of rats. Treatment of rats with diphenyleneiodonium, an inhibitor of NOX, after noise exposure, prevented hearing loss [5]. Pravastatin treatment also decreased NIHL by inhibiting NOX activity in mice [51]. Frequent exposure to vibration also produces hearing disorders. The older guinea pigs were two-fold more sensitive to vibration than younger animals [49]. The combination of noise and vibration during the use of hand-held vibrating tools increased the risk of hearing loss in industrial workers $[6,52]$. Increased oxidative stress and chronic inflammation are also associated with ageing [53], and age-related cochlear structural alterations and degeneration of sensory and neural cells also occurred [54] that resembles normal aging. Hearing loss occurred due to increased oxidative stress in a model of aging rats. In addition, accumulation of mutated mitochondrial DNA was found in the peripheral and central auditory cells [55-57].

Cisplatin caused hearing loss by generating free radicals. Treatment with this drug significantly depressed the levels of antioxidant enzymes, superoxide dismutase (SOD), glutathione peroxidase, glutathione reductase, glutathione transferase and catalase, and enhanced the levels of lipid peroxidation [58]. Carboplatin treatment 
likewise decreased glutathione content [59]. Cisplatin treatment also reduced the intracellular levels of nicotinamide adenine dinucleotide (NAD+); thereby, interfered with energy metabolism. Activation of NAD $(P) H$ : quinone oxidoreductase 1 (NQO1) by beta-lapachone that exhibits antioxidant and anti-inflammation activities, protected against cisplatin-induced ototoxicity by increasing the levels NAD+ and sirtuin-1 protein [60].

A role for oxidative stress in Meniere's disease (MD) is supported by the fact that free radical scavengers such as rebamipide, vitamin $\mathrm{C}$, and glutathione, when administered orally for 8 weeks to patients with poorly controlled MD, improved tinnitus and prevented hearing loss [61].

\section{Evidence for the Role of Inflammation in Hearing Disorders}

Inflammation also plays an important role in hearing disorders induced by noise, drugs, and advancing age. Noise exposure can damage cochlear function by inducing inflammation in animal models $[7,62]$. This is supported by the fact that exposure to noise increased the levels of intracellular adhesion molecules and migration of leukocytes. Intense noise exposure can also activate the nuclear transcription factor-kappaB (NF-kB) in the cochlea of mice that causes overexpression of pro-inflammatory products including intracellular adhesion molecule-1 (ICAM-1) and vascular cell adhesion molecule-1 (VCAM-1) and inducible nitric oxide synthase (iNOS) in the inner ear that contribute to the hearing loss [8].

Aspirin and other anti-inflammatory drugs prevented gentamicin-induced hearing loss and improved hearing ability $[25,63]$. Pro-inflammatory cytokines and activation of NF-kB contribute to the cisplatin-induced ototoxicity in mice and immortalized cochlear cells in cuture $[9,64]$. Tumor necrosis factor-alpha (TNF- $\alpha$ ) also induced cochlear degeneration after bacterial meningitis. Administration of TNF- $\alpha$ antibody reduced meningitis-induced hearing loss in Mongolian gerbils [10]. Increased levels of TNF- $\alpha$ were also associated with trauma-induced hearing loss. Treatment with dexamethasone reduced TNF- $\alpha$-induced damage to the organ of Corti explants cultures [65]. A study has reported that otosclerosis-induced sensorineural hearing loss is due to the chronic release of TNF- $\alpha$ from the foci of otic capsule $[11,66]$. Chronic inflammatory reactions produce sac dysfunction leading to MD [67]. Increased inflammation in the elder individuals was associated with age-related hearing loss [12] and sensorineural hearing loss [13]. Polymorphism of interleukin-6 (IL-6) increased the sensitivity of noise-induced hearing disorders in individuals over the age of 60 years [68].

\section{Evidence for the Role of Glutamate in Hearing Disorders}

When the hair cells are injured, glutamate transmission responsible for converting vibration sound into electrical signal, is enhanced. Glutamate at high concentrations is neurotoxic. Damage to the peripheral auditory and somatosensory systems causes imbalance between excitatory and inhibitory neurotransmitters in the mid brain auditory cortex and brain stem. This imbalance in neurotransmission can cause hyperactivity in the auditory cortex leading to the perception of phantom sounds (tinnitus). Intense noise causes release of excessive amounts of glutamate that damage the inner hair cells-auditory synapses. Kynurenate, a glutamate antagonist, protected guinea pigs against NIHL [14]. The glutamate-aspartate transporter (GLAST) that plays an important role in maintaining the normal levels of glutamate was decreased in the cochlea after exposure to noise leading to increased accumulation of glutamate in the perilymphs. The resulting increased levels of glutamate were associated with an enhanced rate of pro-

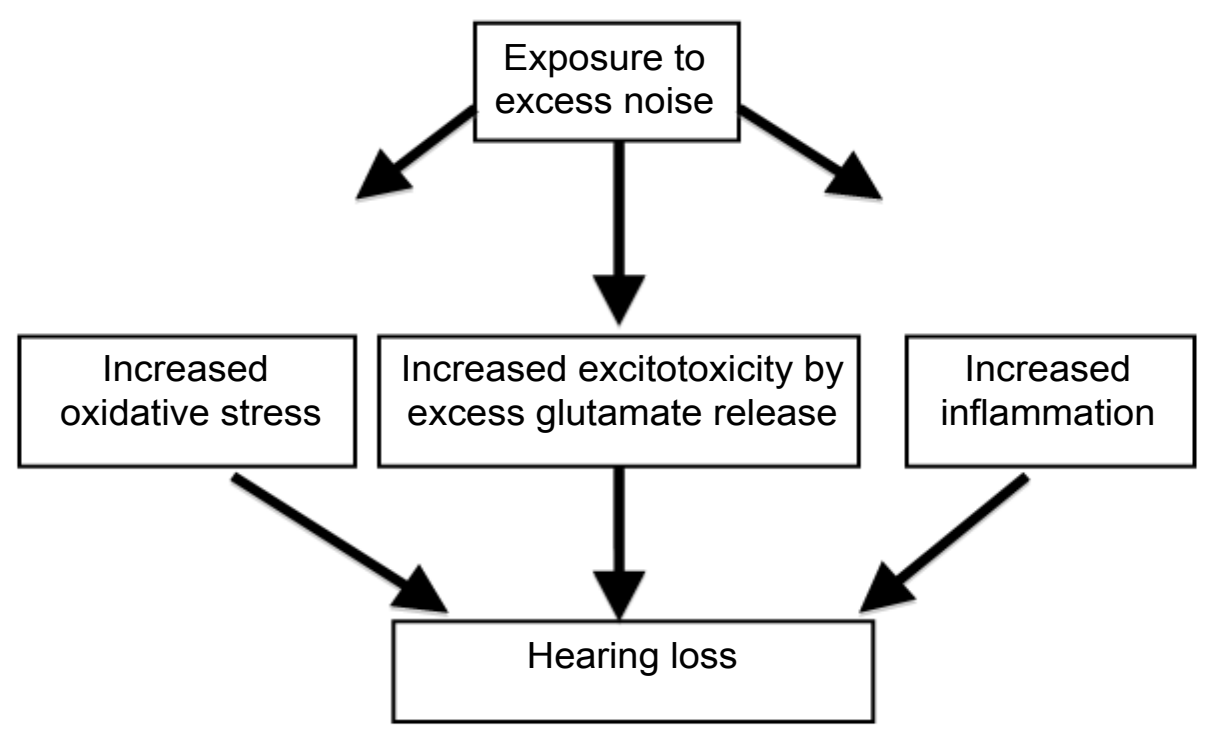

Figure 1: Diagrammatic representation of noise-induced hearing loss pathways. 
gression of hearing loss [15]. Treatment with riluzole, an inhibitor of glutamatergic neurotransmission, protected guinea pigs against NIHL [69]. Treatment with D (-)-2-amino-5-phosphonopentanoic acid (D-AP5), a selective inhibitor of glutamate receptor $\mathrm{N}$-methyl D-aspartate (NMDA) receptor, attenuated noise-induced tinnitus [16]. Diagrammatic representation of noise-induced biochemical events leading to hearing loss is represented in Figure 1.

Additional pre-clinical and clinical studies should be performed to substantiate the role of oxidative stress, chronic inflammation, and glutamate in hearing disorders, using exposure to noise as an example of the ototoxic agent. The levels of markers of oxidative damage, pro-inflammatory cytokines, and glutamate in the plasma of same subject before and after exposure to noise for the prevention studies, and in combination with standard care, for improving the management of hearing loss studies, should be measured.

\section{Diverse Actions and Cellular Distributions of Antioxidants in the Body}

The body protects against oxidative damage by antioxidant compounds derived from the diet as well as made in the body, and antioxidant enzymes made in the body. Antioxidant compounds reduce oxidative stress by a mechanism in part different from that of antioxidant enzymes. They destroy free radicals by donating electron to unpaired state of the free radicals. On the other hand, antioxidant enzymes destroy free radicals by catalysis converting them to the harmless molecules (such as to water and oxygen). Some antioxidant compounds also reduce chronic inflammation [70-74]. Different antioxidants have different affinities for free radicals depending upon their location in the cellular compartments. Water-soluble antioxidants such as vitamin $\mathrm{C}$ and glutathione protect molecules in the aqueous environment of the cells, whereas lipid soluble antioxidants such as vitamin A and vitamin $E$ protect molecules in the lipid environment of the cells. Vitamin E was more effective in quenching free radicals in a reduced oxygenated cellular environment, whereas vitamin $\mathrm{C}$ and vitamin A were more effective in a higher oxygenated environment of the cells [75]. Vitamin $\mathrm{C}$ is important for recycling the oxidized form of vitamin $\mathrm{E}$ to the antioxidant form, [76]. In addition, antioxidants produce cell protective proteins by upregulating or down regulating different microRNAs [77]. For example, some antioxidants can activate Nrf2 by upregulating miR-200a that inhibits its target protein Keap1 [78], whereas others activate Nrf2 by downregulating miR-21 that binds with 3-UTR Nrf2 mRNA [78].

Evidence for the Role of Antioxidants in Hearing Disorders

\section{Animal studies}

Vitamin E treatment reduced cochlear damage in NIHL $[17,79]$, and in hearing loss induced by cisplatin
$[18,80]$ and gentamicin $[81,82]$. Alpha-lipoic acid treatment protected against NIHL and carboplatin-induced hearing loss in animals $[19,83,84]$. The role of $\mathrm{N}$-acetylcysteine (NAC) in reducing NIHL has been reviewed [42]. Treatment with (NAC) significantly reduced noise-induced hair cell loss in cochlear cells of rats and guinea pigs [20]. A combination of acetyl-L-carnitine and NAC also provided protection against hearing loss induced by noise, cisplatin, and aminoglycoside $[85,86]$.

Coenzyme Q10 [21], Idebenone, a synthetic analog of coenzyme Q10 [87], and the soluble form of coenzyme Q10 were effective in reducing hypoxia-induced hearing loss and in NIHL [88]. The combination of vitamin E and idebenone was additive in protecting against NIHL, suggesting that these two antioxidants act by different mechanisms [89]. Oral administration of MitQ, a mitochondria-targeted derivative of ubiquinone, reduced gentamicin-induced hearing disorders by protecting the cochlea [22].

Vitamin C also protected against NIHL in albino guinea pigs [23]. D-methionine attenuated noise-induced oxidative stress and functional loss in the cochlea of mice [90]. Treatment with resveratrol reduced NIHL by decreasing cyclooxygenase-2 (COX-2) levels [24]. Folic acid deficiency induced premature hearing loss by increasing the levels of oxidative stress and homocysteine in mice [91]. Indeed, supplementation with folic acid reduced hearing disorders by reducing oxidative stress and homocysteine levels [92].

Caloric restriction and treatment with individual antioxidants, such as vitamin E, vitamin C, acetyl-Lcarnitine, alpha-lipoic acid and melatonin improved auditory sensitivity to sound, reduced mitochondrial DNA deletion and loss of hair cells in aging rats [93-95]. In a mice model of premature aging, age-related hearing loss occurred. Treatment with n-acetyl-L-carnitine failed to protect against hearing loss in these animals [96]. Taken together these reports show that a marked degree of protection against NIHL can be attained by a variety of antioxidants and related compounds.

\section{Human studies}

In a prospective randomized study, intravenous administration of magnesium sulfate improved hearing recovery in patients with idiopathic sudden sensorineural hearing loss [97]. Coenzyme Q10 delayed the progression of hearing loss in patients with a genetic defect, $7445 \mathrm{~A} \rightarrow$ Gmitochondrial mutation [26]. The use of glutamate antagonists, steroids and antioxidants may be useful in the management of hearing loss and tinnitus [98]. An oral supplementation with antioxidants (vitamin E, vitamin C, beta-carotene and phospholipids) reduced the subjective discomfort and tinnitus intensity in patients with idiopathic tinnitus [27]. NAC protected against aminoglycoside-induced ototoxicity in hemodialysis patients [99]. An antioxidant mixture containing 
reduced glutathione, alpha-lipoic acid, cysteine, and other antioxidants improved the symptoms of MD [100]. A combination of vitamins $A, C$ and $E$, and selenium in combination with standard therapy improved hearing gain more that that produced by standard therapy alone in patients with idiopathic sensorineural hearing loss [28]. Intravenous administration of high dose vitamin C in combination with steroid therapy improved hearing gain more than that produced by steroid therapy alone [29]. Vitamin E supplementation and carbogen (5\% $\mathrm{CO}_{2}$ $+95 \% \mathrm{O}_{2}$ ) breathing reduced noise-induced hearing loss [30]. A commercial preparation of multiple micronutrients reduced symptoms of tinnitus in humans [31].

In order to optimally reduce oxidative stress and inflammation in post-traumatic disorders (PTSDs) and traumatic brain injury (TBI), simultaneous elevation of the levels of antioxidant enzymes through an activation of the Nrf2/ARE (nuclear transcriptional factor-2/antioxidant response element) pathway, as well as enhancing the levels of dietary and endogenous antioxidant compounds may be essential [50]. A similar strategy may be needed for reducing hearing loss in humans.

\section{Regulation of Activation of Nrf2}

Since an elevation of the levels of antioxidant enzymes and other cytoprotective enzymes requires activation of Nrf2, this factor is briefly reviewed. The nuclear transcriptional factor, Nrf2 (nuclear factorerythroid-2- related factor 2) belongs to the Cap 'N'Collar (CNC) family that contains a conserved basic leucine zipper (bZIP) transcriptional factor [100]. Under physiological condition, Nrf2 is associated with Kelchlike ECH associated protein 1 (Keap1), which acts as an inhibitor of Nrf2 [101]. Keap1 protein serves as an adaptor to link Nrf2 to the ubiquitin ligase Cul-Rbx1 complex for degradation by proteasomes and maintains the steady levels of Nrf2 in the cytoplasm. Nrf2-keap1 complex is primarily located in the cytoplasm. Keap1 acts as a sensor for ROS/electrophilic stress.

\section{Activation of Nrf2 by a ROS-dependent mechanism}

Normally, during acute oxidative stress, ROS is needed to activate Nrf2 which then dissociates itself from Keap1-Cul-Rbx1 complex and translocates in the nucleus where it heterodimerizes with a small Maf protein, and binds with the ARE (antioxidant response element) leading to increased expression of target genes coding for several cytoprotective enzymes including antioxidant enzymes [102-105]. Thus, activation of Nrf2 during acute oxidative stress is likely to protect the cochlea from oxidative damage.

\section{Binding of Nrf2 with ARE in the nucleus}

Activation of Nrf2 alone may not be sufficient to increase the levels of antioxidant enzymes. Activated Nrf2 must bind with antioxidant response element
(ARE) in the nucleus for increasing the expression of its target genes. This binding ability of Nrf2 with ARE was impaired in aged rats and this defect was restored by supplementation with alpha-lipoic acid [106]. It is unknown whether the binding ability of Nrf2 with ARE is impaired in hearing disorders.

\section{Activation of Nrf2 by a ROS-independent mecha- nism}

Activation of Nrf2 by ROS becomes impaired during chronic oxidative stress found in patients with hearing loss [107-109]. This is evidenced by the fact that increased oxidative stress occurs in hearing disorders despite the presence of Nrf2.

\section{MIcroRNAs Regulating the Activation of Nrf2}

Although changes in the expressions of microRNAs are being investigated in hearing disorders, this section focuses on the role of microRNAs in regulating Nrf2 activation. microRNAs (miRs) are evolutionarily conserved small non-coding single-stranded RNAs of approximately 22 nucleotides in length, and are present in all living organisms including humans [110-113]. Each micro RNA binds to its complimentary sequences in the $3^{\prime}$ - untranslated region ( $3^{\prime}$-UTR) of the target mRNA that prevents the formation of its protein, and thus, plays an important role in regulating cell function. It appears that specific microRNAs may regulate the activation of Nrf2 by decreasing the levels of Keap1. The complex of Keap1-Nrf2 in the cytoplasm prevents activation of Nrf2. Over-expression of miR-200a reduced Keap-1 levels allowing Nrf2 to migrate to the nucleus where it binds to the ARE that enhanced the transcription of target cytoprotective genes including antioxidant enzymes [114]. Increased oxidative stress associated with hearing disorders enhanced the expression of miR153 and reduced the expression of Nrf2 by binding to its 3 '-UTR region of Nrf2 mRNA [115]. Mutation in miR-153 restored the oxidative stress-induced reduction in Nrf2 activity.

\section{Antioxidant Compounds Regulating Activation of Nrf2}

During chronic oxidative stress, activation of Nrf2 becomes unresponsive to ROS. Antioxidant compounds activate Nrf2 by a ROS-independent mechanism. Some of them are listed here.

\section{Antioxidant compounds that activate Nrf2 by a ROS-independent mechanism}

Some examples are vitamin E and genistein [116], alpha-lipoic acid [106], curcumin [117], resveratrol $[118,119]$, omega-3-fatty acids, glutathione [120,121], glutathione [122], NAC [123], coenzyme Q10 [124], and several plant-derived phytochemicals with antioxidant activities, such as epigallocatechin-3-gallate, carestol, kahweol, cinnamonyl-based compounds, zerumbone, 


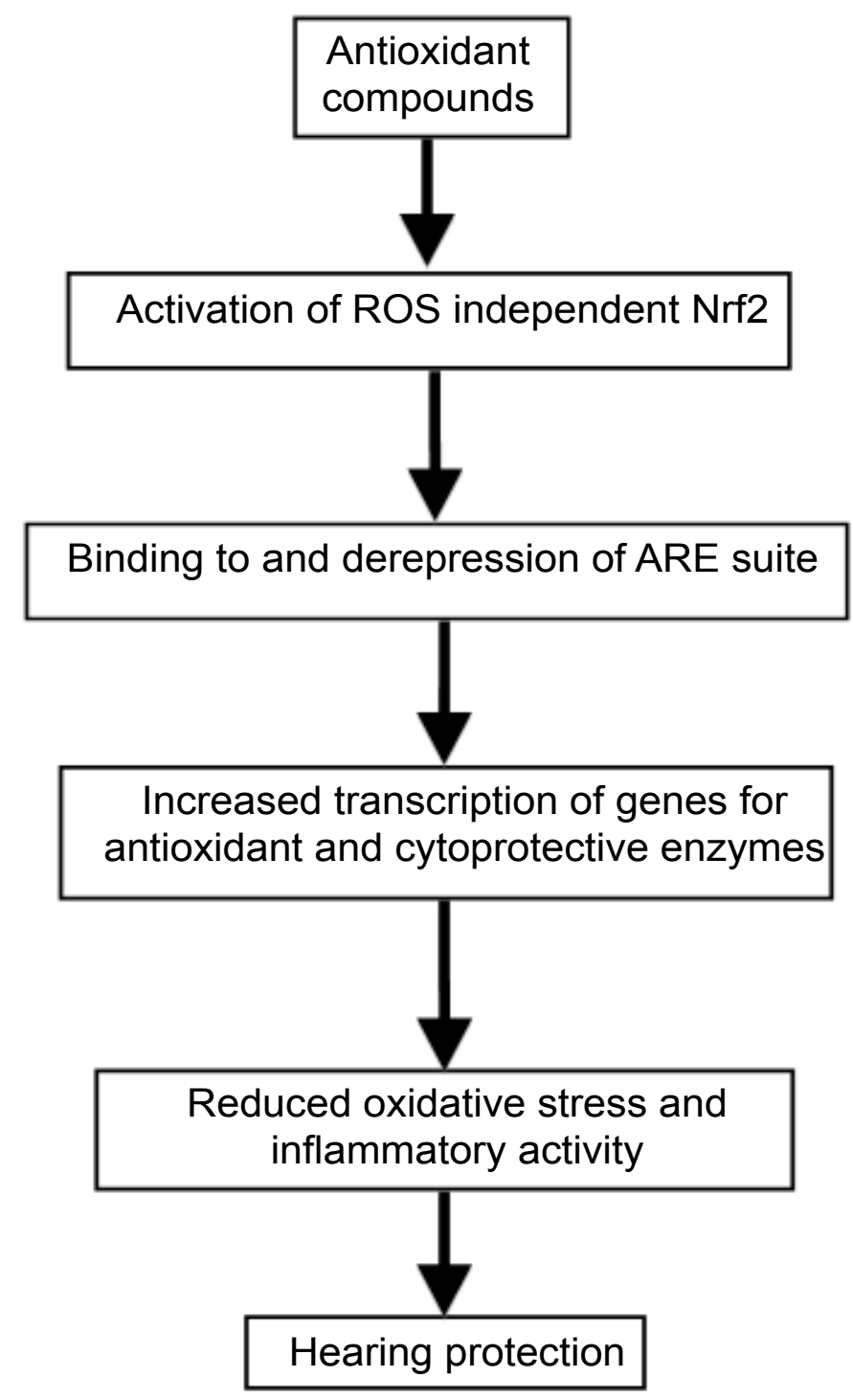

Figure 2: Proposed pathway of protection against hearing loss by antioxidant micronutrients.

lycopene and carnosol [125,126], genistein [116], allicin, a major organosulfur compound found in garlic [127], sulforaphane, a organosulfur compound, found in cruciferous vegetables [128], and kavalactones (methysticin, kavain and yangonin) [129]. The steps whereby ROS-independent activation of Nrf2 may be protective against hearing loss are depicted in Figure 2.

\section{L-carnitine activates Nrf2 by a ROS-dependent mechanism}

L-carnitine activates Nrf2 by a ROS-dependent mechanism [130], probably by generating transient ROS.

\section{Reducing Oxidative Stress Levels}

Activation of Nrf2 may not be sufficient to optimally reduce oxidative stress, because antioxidants compounds are also decreased during chronic oxidative stress [131-133]; therefore, their levels must also be simultaneously elevated.

\section{Reducing Inflammation levels}

Activation of Nrf2 [134,135] and some individual antioxidant compounds reduced chronic inflammation [70-74,136,137].

\section{Activation of Nrf2 in auditory cells}

In Nrf2 deleted mice (-/-) hair cells become more sensitive to noise-induced oxidative damage in comparison to wild-type mice. Pre-treatment with an activator of Nrf2 preserved integrity of hair cells and improved hearing levels in wild-type mice but not in Nrf2 deleted mice (-/-). These results suggest that high activity of Nrf2 in chochlear protects against noise-induced hearing loss [138].

Cisplatin can cause hearing loss by increasing levels of oxidative damage and pro-inflammatory cytokines in hair cells. Pre-treatment with an activator of Nrf2, such as Erdosteine [139], flunarizine [140], Ebselen [141], Ginkgolide B, a major component of Ginkgo biloba [142], and phloretin [143] protected hair cells (HE1OC1) by reducing oxidative damage, pro-inflammatory cytokines, inhibition of pro-apoptotic expression, and enhancing the levels of cytoprotective enzymes including antioxidant enzymes. 
Increased oxidative stress contributes to cochlear damage, including age-related hearing loss and gentamicin-induced ototoxicity. The Nrf2-knockout mice maintained normal auditory thresholds at an their age of 3 months; however, their hearing ability was significantly impaired as they grow older (6 and 11 months) in comparison to age-matched wild type mice [144]. In addition, the number of hair cells and spiral ganglion cells was markedly decreased in Nrf2-knockout mice. In the explants culture of Corte, treatment with gentamicin ehanced the loss of hair cells in Nrf2-deficient tissue more than that found in wild-type mice. Activation of Nrf2 occurred only in the wild-type mice, but not in Nrf2-knockout mice. These results further suggest importance of Nrf2 in the auditory for protection of hearing disorders.

\section{Reducing Glutamate Levels}

Some antioxidants decrease the release of glutamate as well as its neurotoxicity [145-147]. In addition, certain B-vitamins can also decreased the release of glutamate $[148,149]$.

\section{Proposed Micronutrients for Reducing Hearing Disorders}

Because of failure to produce consistent benefit in improving the symptoms of hearing disorders with one or two micronutrients, a comprehensive micronutrient mixture is proposed. This mixture contains multiple dietary antioxidant compounds (vitamin A, natural mixed carotenoids, vitamin $C$, vitamin $D$, vitamin $E$, curcumin, resveratrol), endogenous antioxidants (alpha-lipoic acid, L-carnitine, and coenzyme Q10), and a synthetic antioxidant $\mathrm{N}$-acetylcysteine (NAC), omega-3-fatty acids, and all B-vitamins. This mixture of micronutrients may optimally reduce oxidative stress and chronic inflammation by simultaneously enhancing the levels of antioxidant enzymes through activation of the Nrf2/ARE pathway, and elevating the levels of antioxidant compounds. The same micronutrient mixture may also reduce the release and toxicity of glutamate.

\section{Prevention of Hearing Disorders}

\section{Primary prevention}

The purpose of primary prevention is to protect healthy individuals from developing hearing disorders. Older individuals, musicians, industrial workers, troops who are likely to be employed in the war zones, individuals who are likely to receive certain antibiotics for their health conditions, and individuals carrying mutations in genes responsible for hearing loss, are suitable subjects for the primary prevention studies.

\section{Prevention of hearing loss in individuals carrying mutated genes}

At present, there are no strategies to delay the onset of hearing loss in individuals with mutated genes. The proposed mixture of micronutrients may be effective in preventing or delaying the onset of symptoms of hearing disorders in these individuals. This possibility is indirectly supported by an experiment on the fruit flies described here.

The gene HOP (TUM-1) is essential for the development of Drosophila melanogaster (fruit fly). A mutation in this gene markedly increases the risk of developing a leukemia-like tumor in female flies. In collaboration with Dr. Bhattacharya of NASA Moffat Field, CA, we observed that whole-body irradiation of these flies with proton radiation dramatically increased the incidence of cancer compared to that observed in un-irradiated female flies. Treatment with a mixture of multiple antioxidants before and after irradiation blocked the incidence of proton radiation-induced cancer in female fruit flies [150].

\section{Secondary prevention}

The purpose of secondary prevention is to stop or slow the progression of hearing disorders after exposure to ototoxic agents. Individuals who have been exposed to such agents, but have not developed any hearing problems, and are not taking any medication, are suitable subjects for the secondary prevention of hearing disorders. The micronutrient mixture suggested for the primary prevention studies is also proposed for the secondary prevention studies.

\section{Proposed micronutrients mixture in combination with standard care}

The patients with hearing disorders who are receiving standard care are suitable for this study. The micronutrient mixture suggested for the primary prevention studies is also proposed in combination with standard care for the improved management studies.

\section{Conclusions}

Published studies suggest that increased oxidative stress, chronic inflammation, and glutamate play a key role in the initiation and progression of hearing disorders, irrespective of the types of ototoxic agents or health conditions. Some antioxidant compounds used in animal and human studies to prevent or treat hearing loss may activate Nrf2, but this may not be sufficient to optimally reduce oxidative stress, chronic inflammation, and glutamate release. This may be due to the fact that the levels of dietary and endogenous antioxidant compounds are also depleted in a high oxidative environment found in patients with hearing disorders. Their levels cannot be increased by supplementation with one or two antioxidant compounds. The proposed micronutrient mixture may serve to optimally reduce oxidative stress and chronic inflammation by simultaneously enhancing the levels of antioxidant enzymes through activating the Nrf2/ARE pathway, and dietary 
and endogenous antioxidant compounds. Such a micronutrient mixture may also reduce the release and toxicity of glutamate. The efficacy of this mixture of micronutrients should be tested in the primary prevention, secondary prevention, as well as in combination with standard care in improved management studies.

\section{Conflicts}

The author is a Chief Scientific Officer of Engage Global, Provo, Utah.

\section{Acknowledgement}

The author thanks Professor Stephen C. Bondy, University of California, Irvine, for reviewing and editing this manuscript.

This research did not receive any specific grant from funding agencies in the public, commercial or not-forprofit sector.

\section{References}

1. Clerici WJ, DiMartino DL, Prasad MR (1995) Direct effects of reactive oxygen species on cochlear outer hair cell shape in vitro. Hear Res 84: 30-40.

2. Henderson D, Bielefeld EC, Harris KC, Hu BH (2006) The role of oxidative stress in noise-induced hearing loss. Ear Hear 27: 1-19.

3. Van Campen LE, Murphy WJ, Franks JR, Mathias PI, Toraason MA (2002) Oxidative DNA damage is associated with intense noise exposure in the rat. Hear Res 164: 2938.

4. Neri S, Signorelli S, Pulvirenti D, Mauceri B, Cilio D, et al (2006) Oxidative stress, nitric oxide, endothelial dysfunction and tinnitus. Free Radic Res 40: 615-618.

5. Vlajkovic SM, Lin SC, Wong AC, Wackrow B, Thorne PR (2013) Noise-induced changes in expression levels of NADPH oxidases in the cochlea. Hear Res 304: 145-152.

6. Turcot A, Girard SA, Courteau M, Baril J, Larocque R (2015) Noise-induced hearing loss and combined noise and vibration exposure. Occup Med (Lond) 65: 238-244.

7. Yamamoto $H$, Omelchenko I, Shi X, Nuttall AL (2009) The influence of NF-kappaB signal-transduction pathways on the murine inner ear by acoustic overstimulation. J Neurosci Res 87: 1832-1840.

8. Masuda M, Nagashima R, Kanzaki S, Fujioka M, Ogita K, et al. (2006) Nuclear factor-kappa B nuclear translocation in the cochlea of mice following acoustic overstimulation. Brain Res 1068: 237-247.

9. Kim HJ, So HS, Lee JH, Park C, Lee JB, et al. (2008) Role of proinflammatory cytokines in cisplatin-induced vestibular hair cell damage. Head Neck 30: 1445-1456.

10. Aminpour S, Tinling SP, Brodie HA (2005) Role of tumor necrosis factor-alpha in sensorineural hearing loss after bacterial meningitis. Otol Neurotol 26: 602-609.

11. Sziklai I, Batta TJ, Karosi T (2009) Otosclerosis: An organspecific inflammatory disease with sensorineural hearing loss. Eur Arch Otorhinolaryngol 266: 1711-1718.

12. Verschuur C, Agyemang-Prempeh A, Newman TA (2014) Inflammation is associated with a worsening of presbycusis: Evidence from the MRC national study of hearing. Int $\mathrm{J}$ Audiol 53: 469-475.
13. Masuda M, Kanzaki S, Minami S, Kikuchi J, Kanzaki J, et al. (2012) Correlations of inflammatory biomarkers with the onset and prognosis of idiopathic sudden sensorineural hearing loss. Otol Neurotol 33: 1142-1150.

14. Puel JL, Ruel J, Gervais d'Aldin C, Pujol R (1998) Excitotoxicity and repair of cochlear synapses after noisetrauma induced hearing loss. Neuroreport 9: 2109-2114.

15. Hakuba N, Koga K, Gyo K, Usami SI, Tanaka K (2000) Exacerbation of noise-induced hearing loss in mice lacking the glutamate transporter GLAST. J Neurosci 20: 8750-8753.

16. Brozoski TJ, Wisner KW, Odintsov B, Bauer CA (2013) Local NMDA receptor blockade attenuates chronic tinnitus and associated brain activity in an animal model. PLoS One 8: e77674.

17. Hou F, Wang S, Zhai S, Hu Y, Yang W, et al. (2003) Effects of alpha-tocopherol on noise-induced hearing loss in guinea pigs. Hear Res 179: 1-8.

18. Kalkanis JG, Whitworth C, Rybak LP (2004) Vitamin E reduces cisplatin ototoxicity. Laryngoscope 114: 538-542.

19. Husain K, Whitworth C, Somani SM, Rybak LP (2005) Partial protection by lipoic acid against carboplantininduced ototoxicity in rats. Biomed Environ Sci 18: 198-206.

20. Kopke RD, Jackson RL, Coleman JK, Liu J, Bielefeld EC, et al. (2007) NAC for noise: From the bench top to the clinic. Hear Res 226: 114-125.

21. Sato K (1988) Pharmacokinetics of coenzyme Q10 in recovery of acute sensorineural hearing loss due to hypoxia. Acta Otolaryngol Suppl 458: 95-102.

22. Ojano-Dirain CP, Antonelli PJ, Le Prell CG (2014) Mitochondria-targeted antioxidant MitoQ reduces gentamicin-induced ototoxicity. Otol Neurotol 35: 533-539.

23. McFadden SL, Woo JM, Michalak N, Ding D (2005) Dietary vitamin $\mathrm{C}$ supplementation reduces noise-induced hearing loss in guinea pigs. Hear Res 202: 200-208.

24. Seidman MD, Tang W, Bai VU, Ahmad N, Jiang $H$, et al. (2013) Resveratrol decreases noise-induced cyclooxygenase-2 expression in the rat cochlea. Otolaryngol Head Neck Surg 148: 827-833.

25. Wang $X$, Truong T, Billings PB, Harris JP, Keithley EM (2003) Blockage of immune-mediated inner ear damage by etanercept. Otol Neurotol 24: 52-57.

26. Angeli SI, Liu XZ, Yan D, Balkany T, Telischi F (2005) Coenzyme Q-10 treatment of patients with a 7445A--$>G$ mitochondrial DNA mutation stops the progression of hearing loss. Acta Otolaryngol 125: 510-512.

27. Savastano M, Brescia G, Marioni G (2007) Antioxidant therapy in idiopathic tinnitus: Preliminary outcomes. Arch Med Res 38: 456-459.

28. Kaya H, Koc AK, Sayin I, Gunes S, Altintas A, et al. (2015) Vitamins $A, C$, and $E$ and selenium in the treatment of idiopathic sudden sensorineural hearing loss. Eur Arch Otorhinolaryngol 272: 1119-1125.

29. Kang HS, Park JJ, Ahn SK, Hur DG, Kim HY (2013) Effect of high dose intravenous vitamin $C$ on idiopathic sudden sensorineural hearing loss: A prospective single-blind randomized controlled trial. Eur Arch Otorhinolaryngol 270: 2631-2636.

30. Kapoor N, Mani KV, Shyam R, Sharma RK, Singh AP, et al. (2011) Effect of vitamin E supplementation on carbogeninduced amelioration of noise induced hearing loss in man. Noise \& Health 13: 452-458. 
31. Haase GM, Prasad KN, Cole WC, Baggett-Strehlau, Wyatt SE (2011) Antioxidant micronutrient impact on hearing disorders: Concept, rationale and evidence. Am J Otolaryngol 32: 55-61.

32. Chen P, Wang S, Zhang Y, Huang H, Zhang C, et al. (2015) [Intratympanic versus systemic steroid initial treatment for idiopathic sudden hearing loss: A meta-analysis]. Lin Chung Er Bi Yan Hou Tou Jing Wai Ke Za Zhi 29: 1970-1977.

33. Langguth B, Elgoyhen AB (2012) Current pharmacological treatments for tinnitus. Expert Opin Pharmacother 13: 2495-2509.

34. Guitton MJ, Dudai Y (2007) Blockade of cochlear NMDA receptors prevents long-term tinnitus during a brief consolidation window after acoustic trauma. Neural Plast 2007: 80904.

35. Bing D, Lee SC, Campanelli D, Xiong H, Matsumoto M, et al. (2015) Cochlear NMDA receptors as a therapeutic target of noise-induced tinnitus. Cell Physiol Biochem 35: 1905-1923.

36. Kirkby-Strachan G, Que-Hee C (2016) Implantable hearing devices - An update. Aust Fam Physician 45: 370-373.

37. Rezaei M, Rashedi V, Morasae EK (2016) Reading skills in Persian deaf children with cochlear implants and hearing aids. Int J Pediatr Otorhinolaryngol 89: 1-5.

38. Walravens E, Keidser G, Hickson L (2016) Provision, perception and use of trainable hearing aids in Australia: A survey of clinicians and hearing impaired adults. Int $\mathrm{J}$ Audiol 55: 787-795.

39. GM de Carvalho, Guimaraes AC, Duarte AS, Muranaka EB, Soki MN, et al. (2013) Hearing preservation after cochlear implantation: UNICAMP outcomes. Int J Otolaryngol 2013: 107186.

40. Colletti V, Fiorino FG, Saccetto L, Giarbini N, Carner M (1999) Improved auditory performance of cochlear implant patients using the middle fossa approach. Audiology 38: 225-234.

41. Prasad KN (2016) Simultaneous activation of Nrf2 and elevation of antioxidant compounds for reducing oxidative stress and chronic inflammation in human Alzheimer's disease. Mech Ageing Dev 153: 41-47.

42. Diao MF, Liu HY, Zhang YM, Gao WY (2003) [Changes in antioxidant capacity of the guinea pig exposed to noise and the protective effect of alpha-lipoic acid against acoustic trauma]. Sheng Li Xue Bao 55: 672-676.

43. Henderson D, McFadden SL, Liu CC, Hight N, Zheng XY (1999) The role of antioxidants in protection from impulse noise. Ann N Y Acad Sci 884: 368-380.

44. Ohlemiller KK, McFadden SL, Ding DL, Flood DG, Reaume AG, et al. (1999) Targeted deletion of the cytosolic Cu/Znsuperoxide dismutase gene (Sod1) increases susceptibility to noise-induced hearing loss. Audiol Neurootol 4: 237-246.

45. Yamane $H$, Nakai $Y$, Takayama $M$, Konishi $K$, Iguchi $H$, et al. (1995) The emergence of free radicals after acoustic trauma and strial blood flow. Acta Otolaryngol Suppl 519: 87-92.

46. Minami SB, Yamashita D, Schacht J, Miller JM (2004) Calcineurin activation contributes to noise-induced hearing loss. J Neurosci Res 78: 383-392.

47. Ossowska K, Konieczny J, Wardas J, Pietraszek M, Kuter K, et al. (2007) An influence of ligands of metabotropic glutamate receptor subtypes on parkinsonian-like symptoms and the striatopallidal pathway in rats. Amino Acids 32: 179-188.
48. Kowalska S, Sulkowski W (2001) Tinnitus in noise-induced hearing impairment. Med Pr 52: 305-313.

49. Fagelson MA (2007) The association between tinnitus and posttraumatic stress disorder. Am J Audiol 16: 107-117.

50. Prasad KN (2015) Simultaneous activation of Nrf2 and elevation of antioxidant chemicals in management of post-traumatic stress disorders and traumatic brain injury. BMMR 18: 116-127.

51. Park JS, Kim SW, Park K, Choung YH, Jou I, et al. (2012) Pravastatin attenuates noise-induced cochlear injury in mice. Neuroscience 208: 123-132.

52. Pettersson $H$, Burstrom L, Hagberg $M$, Lundstrom $R$, Nilsson T (2014) Risk of hearing loss among workers with vibration-induced white fingers. Am J Ind Med 57: 13111318.

53. Le T, Keithley EM (2007) Effects of antioxidants on the aging inner ear. Hear Res 226: 194-202.

54. Zou J, Bretlau P, Pyykko I, Starck J, Toppila E (2001) Sensorineural hearing loss after vibration: An animal model for evaluating prevention and treatment of inner ear hearing loss. Acta Otolaryngol 121: 143-148.

55. Du Z, Yang Q, Liu L, Li S, Zhao J, et al. (2015) NADPH oxidase 2-dependent oxidative stress, mitochondrial damage and apoptosis in the ventral cochlear nucleus of D-galactose-induced aging rats. Neuroscience 286: 281292.

56. Chen B, Zhong Y, Peng W, Sun Y, Kong WJ (2010) Agerelated changes in the central auditory system: Comparison of $D$-galactose-induced aging rats and naturally aging rats. Brain Res 1344: 43-53.

57. Zhong Y, Hu YJ, Chen B, Peng W, Sun Y, et al. (2011) Mitochondrial transcription factor $A$ overexpression and base excision repair deficiency in the inner ear of rats with D-galactose-induced aging. FEBS J 278: 2500-2510.

58. Minami SB, Sha SH, Schacht J (2004) Antioxidant protection in a new animal model of cisplatin-induced ototoxicity. Hear Res 198: 137-143.

59. Husain K, Scott RB, Whitworth C, Somani SM, Rybak LP (2001) Dose response of carboplatin-induced hearing loss in rats: Antioxidant defense system. Hear Res 151: 71-78.

60. Kim HJ, Oh GS, Shen A, Lee SB, Choe SK, et al. (2014) Augmentation of $\mathrm{NAD}(+)$ by $\mathrm{NQO} 1$ attenuates cisplatinmediated hearing impairment. Cell Death Dis 5: e1292.

61. Takumida M, Anniko M, Ohtani M (2003) Radical scavengers for Meniere's disease after failure of conventional therapy: A pilot study. Acta Otolaryngol 123: 697-703.

62. Shi X, Nuttall AL (2007) Expression of adhesion molecular proteins in the cochlear lateral wall of normal and PARP-1 mutant mice. Hear Res 224: 1-14.

63. Chen Y, Huang WG, Zha DJ, Qiu JH, Wang JL, et al. (2007) Aspirin attenuates gentamicin ototoxicity: From the laboratory to the clinic. Hear Res 226: 178-182.

64. So H, Kim H, Lee JH, Park C, Kim Y, et al. (2007) Cisplatin cytotoxicity of auditory cells requires secretions of proinflammatory cytokines via activation of ERK and NFkappaB. J Assoc Res Otolaryngol 8: 338-355.

65. Haake SM, Dinh CT, Chen S, Eshraghi AA, Van De Water TR (2009) Dexamethasone protects auditory hair cells against TNFalpha-initiated apoptosis via activation of PI3K/ Akt and NFkappaB signaling. Hear Res 255: 22-32.

66. Van De Water TR, Dinh CT, Vivero R, Hoosien G, Eshraghi 
AA, et al. (2009) Mechanisms of hearing loss from trauma and inflammation: Otoprotective therapies from the laboratory to the clinic. Acta Otolaryngol 130: 308-311.

67. Derebery MJ (1996) Allergic and immunologic aspects of Meniere's disease. Otolaryngol Head Neck Surg 114: 360365.

68. Braga MP, Maciel SM, Marchiori LL, Poli-Frederico RC (2014) Association between interleukin-6 polymorphism in the $-174 \mathrm{G} / \mathrm{C}$ region and hearing loss in the elderly with a history of occupational noise exposure. Braz J Otorhinolaryngol 80: 373-378.

69. Ruel J, Wang J, Pujol R, Hameg A, Dib M, et al. (2005) Neuroprotective effect of riluzole in acute noise-induced hearing loss. Neuroreport 16: 1087-1090.

70. Devaraj S, Tang R, Adams-Huet B, Harris A, Seenivasan $T$, et al. (2007) Effect of high-dose a-tocopherol supplementation on biomarkers of oxidative stress and inflammation and carotid atherosclerosis in patients with coronary artery disease. Am J Clin Nutr 86: 1392-1398.

71. Fu Y, Zheng S, Lin J, Ryerse J, Chen A (2008) Curcumin protects the rat liver from $\mathrm{CCl} 4$-caused injury and fibrogenesis by attenuating oxidative stress and suppressing inflammation. Mol Pharmacol 73: 399-409.

72. Lee HS, Jung KK, Cho JY, Rhee MH, Hong S, et al. (2007) Neuroprotective effect of curcumin is mainly mediated by blockade of microglial cell activation. Pharmazie 62: 937942.

73. Rahman S, Bhatia K, Khan AQ, Kaur M, Ahmad F, et al. (2008) Topically applied vitamin E prevents massive cutaneous inflammatory and oxidative stress responses induced by double application of 12-O-tetradecanoylphorbol13-acetate (TPA) in mice. Chem Biol Interact 172: 195-205.

74. Zhu J, Yong W, Wu X, Yu Y, Lv J, et al. (2008) Antiinflammatory effect of resveratrol on TNF-alpha-induced MCP-1 expression in adipocytes. Biochem Biophys Res Commun 369: 471-477.

75. Vile GF, Winterbourn CC (1988) Inhibition of adriamycinpromoted microsomal lipid peroxidation by beta-carotene, alpha-tocopherol and retinol at high and low oxygen partial pressures. FEBS Lett 238: 353-356.

76. Niki E (1987) Interaction of ascorbate and alpha-tocopherol. Ann N Y Acad Sci 498: 186-199.

77. Prasad KN (2017) Oxidative stress and pro-inflammatory cytokines may act as one of the signals for regulating microRNAs expression in Alzheimer's disease. Mech Ageing Dev 162: 63-71.

78. Wu H, Kong L, Tan Y, Epstein PN, Zeng J, et al. (2016) C66 ameliorates diabetic nephropathy in mice by both upregulating NRF2 function via increase in miR-200a and inhibiting miR-21. Diabetologia 59: 1558-1568.

79. Scholik AR, Lee US, Chow CK, Yan HY (2004) Dietary vitamin $E$ protects the fathead minnow, Pimephales promelas, against noise exposure. Comp Biochem Physiol C Toxicol Pharmacol 137: 313-323.

80. Teranishi MA, Nakashima T (2003) Effects of trolox, locally applied on round windows, on cisplatin-induced ototoxicity in guinea pigs. Int J Pediatr Otorhinolaryngol 67: 133-139.

81. Sergi B, Fetoni AR, Ferraresi A, Troiani D, Azzena GB, et al. (2004) The role of antioxidants in protection from ototoxic drugs. Acta Otolaryngol Suppl 552: 42-45.

82. Fetoni AR, Sergi B, Ferraresi A, Paludetti G, Troiani D (2004) alpha-Tocopherol protective effects on gentamicin ototoxicity: an experimental study. Int J Audiol 43: 166-171.

83. Aabdallah DM, Eid NI (2004) Possible neuroprotective effects of lecithin and alpha-tocopherol alone or in combination against ischemia/reperfusion insult in rat brain. Journal of Biochemical and Molecular Toxicology 18: 273278.

84. Joachims HZ, Segal J, Golz A, Netzer A, Goldenberg D (2003) Antioxidants in treatment of idiopathic sudden hearing loss. Otol Neurotol 24: 572-575.

85. Duan M, Qiu J, Laurell G, Olofsson A, Counter SA, et al. (2004) Dose and time-dependent protection of the antioxidant $\mathrm{N}$-L-acetylcysteine against impulse noise trauma. Hear Res 192: 1-9.

86. Ohinata Y, Yamasoba T, Schacht J, Miller JM (2000) Glutathione limits noise-induced hearing loss. Hear Res 146: 28-34.

87. Sergi B, Fetoni AR, Paludetti G, Ferraresi A, Navarra P, et al. (2006) Protective properties of idebenone in noiseinduced hearing loss in the guinea pig. Neuroreport 17: 857-861.

88. Fetoni AR, Piacentini R, Fiorita A, Paludetti G, Troiani D (2009) Water-soluble Coenzyme Q10 formulation (Q-ter) promotes outer hair cell survival in a guinea pig model of noise induced hearing loss (NIHL). Brain Res 1257: 108116.

89. Fetoni AR, Ferraresi A, Greca CL, Rizzo D, Sergi B, et al. (2008) Antioxidant protection against acoustic trauma by coadministration of idebenone and vitamin E. Neuroreport 19: 277-281.

90. Samson J, Wiktorek-Smagur A, Politanski P, Rajkowska E, Pawlaczyk-Luszczynska M, et al. (2008) Noise-induced time-dependent changes in oxidative stress in the mouse cochlea and attenuation by D-methionine. Neuroscience 152: $146-150$.

91. Martinez-Vega R, Garrido F, Partearroyo T, Cediel R, Zeisel SH, et al. (2015) Folic acid deficiency induces premature hearing loss through mechanisms involving cochlear oxidative stress and impairment of homocysteine metabolism. FASEB J 29: 418-432.

92. Kundu S, Munjal C, Tyagi N, Sen U, Tyagi AC, et al. (2012) Folic acid improves inner ear vascularization in hyperhomocysteinemic mice. Hear Res 284: 42-51.

93. Seidman MD (2000) Effects of dietary restriction and antioxidants on presbyacusis. Laryngoscope 110: 727-738.

94. Seidman MD, Ahmad N, Joshi D, Seidman J, Thawani S, et al. (2004) Age-related hearing loss and its association with reactive oxygen species and mitochondrial DNA damage. Acta Otolaryngol Suppl 552: 16-24.

95. Derin A, Agirdir B, Derin N, Dinc O, Guney K, et al. (2004) The effects of L-carnitine on presbyacusis in the rat model. Clin Otolaryngol Allied Sci 29: 238-241.

96. Davis RR, Kuo MW, Stanton SG, Canlon B, Krieg E, et al. (2007) N-Acetyl L-cysteine does not protect against premature age-related hearing loss in C57BL/6J mice: a pilot study. Hear Res 226: 203-208.

97. Gordin A, Goldenberg D, Golz A, Netzer A, Joachims HZ (2002) Magnesium: a new therapy for idiopathic sudden sensorineural hearing loss. Otol Neurotol 23: 447-451.

98. Seidman MD (1998) Glutamate Antagonists, Steroids, and Antioxidants as Therapeutic Options for Hearing Loss and Tinnitus and the Use of an Inner Ear Drug Delivery System. Int Tinnitus J 4: 148-154. 
99. Tepel M (2007) N-Acetylcysteine in the prevention of ototoxicity. Kidney Int 72: 231-232.

100. Raponi G, Alpini D, Volonte S, Capobianco S, Cesarani A (2003) The role of free radicals and plasmatic antioxidant in Meniere's syndrome. Int Tinnitus J 9: 104-108.

101. Jaramillo MC, Zhang DD (2013) The emerging role of the Nrf2-Keap1 signaling pathway in cancer. Genes Dev 27: 2179-2191.

102. Williamson TP, Johnson DA, Johnson JA (2012) Activation of the Nrf2-ARE pathway by siRNA knockdown of Keap1 reduces oxidative stress and provides partial protection from MPTP-mediated neurotoxicity. Neurotoxicology 33: 272-279.

103. Itoh K, Chiba T, Takahashi S, Ishii T, Igarashi K, et al. (1997) An Nrf2/small Maf heterodimer mediates the induction of phase II detoxifying enzyme genes through antioxidant response elements. Biochemical and Biophysical Research Communications 236: 313-322.

104. Hayes JD, Chanas SA, Henderson CJ, McMahon M, Sun C, et al. (2000) The Nrf2 transcription factor contributes both to the basal expression of glutathione S-transferases in mouse liver and to their induction by the chemopreventive synthetic antioxidants, butylated hydroxyanisole and ethoxyquin. Biochemical Society Transactions 28: 33-41.

105. Chan K, Han XD, Kan YW (2001) An important function of Nrf2 in combating oxidative stress: detoxification of acetaminophen. Proc Natl Acad Sci USA 98: 4611-4616.

106. Suh JH, Shenvi SV, Dixon BM, Liu H, Jaiswal AK, et al. (2004) Decline in transcriptional activity of Nrf2 causes age-related loss of glutathione synthesis, which is reversible with lipoic acid. Proceedings of the National Academy of Sciences of the United States of America 101: 3381-3386.

107. Ramsey CP, Glass CA, Montgomery MB, Lindl KA, Ritson GP, et al. (2007) Expression of Nrf2 in neurodegenerative diseases. J Neuropathol Exp Neurol 66: 75-85.

108. Chen PC, Vargas MR, Pani AK, Smeyne RJ, Johnson DA, et al. (2009) Nrf2-mediated neuroprotection in the MPTP mouse model of Parkinson's disease: Critical role for the astrocyte. Proc Natl Acad Sci U S A 106: 2933-2938.

109. Lastres-Becker I, Ulusoy A, Innamorato NG, Sahin G, Rabano A, et al. (2012) alpha-Synuclein expression and Nrf2 deficiency cooperate to aggravate protein aggregation, neuronal death and inflammation in early-stage Parkinson's disease. Hum Mol Genet 21: 3173-3192.

110. Lee RC, Feinbaum RL, Ambros V (1993) The C. elegans heterochronic gene lin-4 encodes small RNAs with antisense complementarity to lin-14. Cell 75: 843-854.

111. Wightman B, Ha I, Ruvkun G (1993) Posttranscriptional regulation of the heterochronic gene lin-14 by lin-4 mediates temporal pattern formation in C. elegans. Cell 75: 855-862.

112. Macfarlane LA, Murphy PR (2010) MicroRNA: Biogenesis, Function and Role in Cancer. Curr Genomics 11: 537-561.

113. Londin E, Loher P, Telonis AG, Quann K, Clark P, et al. (2015) Analysis of 13 cell types reveals evidence for the expression of numerous novel primate- and tissue-specific microRNAs. Proc Natl Acad Sci U S A 112: E1106-1115.

114. Eades G, Yang M, Yao Y, Zhang Y, Zhou Q (2011) miR200a regulates Nrf2 activation by targeting Keap1 mRNA in breast cancer cells. J Biol Chem 286: 40725-40733.

115. Narasimhan M, Riar AK, Rathinam ML, Vedpathak D,
Henderson G, et al. (2014) Hydrogen peroxide responsive miR153 targets Nrf2/ARE cytoprotection in paraquat induced dopaminergic neurotoxicity. Toxicol Lett 228: 179-191.

116. Xi YD, Yu HL, Ding J, Ma WW, Yuan LH, et al. (2012) Flavonoids protect cerebrovascular endothelial cells through Nrf2 and PI3K from beta-amyloid peptide-induced oxidative damage. Current Neurovascular Research 9: 32-41.

117. Trujillo J, Chirino YI, Molina-Jijon E, Anderica-Romero AC, Tapia E, et al. (2013) Renoprotective effect of the antioxidant curcumin: Recent findings. Redox Biology 1: 448-456.

118. Steele ML, Fuller S, Patel M, Kersaitis C, Ooi L, et al. (2013) Effect of Nrf2 activators on release of glutathione, cysteinylglycine and homocysteine by human U373 astroglial cells. Redox Biology 1: 441-445.

119. Kode A, Rajendrasozhan S, Caito S, Yang SR, Megson IL, et al. (2008) Resveratrol induces glutathione synthesis by activation of Nrf2 and protects against cigarette smokemediated oxidative stress in human lung epithelial cells. Am J Physiol Lung Cell Mol Physiol 294: 478-488.

120. Gao L, Wang J, Sekhar KR, Yin H, Yared NF, et al. (2007) Novel $n-3$ fatty acid oxidation products activate Nrf2 by destabilizing the association between Keap1 and Cullin3. J Biol Chem 282: 2529-2537.

121. Saw CL, Yang AY, Guo Y, Kong AN (2013) Astaxanthin and omega-3 fatty acids individually and in combination protect against oxidative stress via the Nrf2-ARE pathway. Food Chem Toxicol 62: 869-875.

122. Song J, Kang SM, Lee WT, Park KA, Lee KM, et al. (2014) Glutathione protects brain endothelial cells from hydrogen peroxide-induced oxidative stress by increasing nrf2 expression. Exp Neurobiol 23: 93-103.

123. Ji L, Liu R, Zhang XD, Chen HL, Bai H, et al. (2010) $\mathrm{N}$-acetylcysteine attenuates phosgene-induced acute lung injury via up-regulation of Nrf2 expression. Inhal Toxicol 22: 535-542.

124. Choi HK, Pokharel YR, Lim SC, Han HK, Ryu CS, et al. (2009) Inhibition of liver fibrosis by solubilized coenzyme Q10: Role of Nrf2 activation in inhibiting transforming growth factor-beta1 expression. Toxicol Appl Pharmacol 240: 377-384.

125. Jeong WS, Jun M, Kong AN (2006) Nrf2: a potential molecular target for cancer chemoprevention by natural comounds. Antioxid Redox Signal 8: 99-106.

126. Chun KS, Kundu J, Kundu JK, Surh YJ (2014) Targeting Nrf2-Keap1 signaling for chemoprevention of skin carcinogenesis with bioactive phytochemicals. Toxicol Lett 229: 73-84.

127. Li XH, Li CY, Lu JM, Tian RB, Wei J (2012) Allicin ameliorates cognitive deficits ageing-induced learning and memory deficits through enhancing of Nrf2 antioxidant signaling pathways. Neuroscience Letters 514: 46-50.

128. Bergstrom P, Andersson HC, Gao Y, Karlsson JO, Nodin C, et al. (2011) Repeated transient sulforaphane stimulation in astrocytes leads to prolonged Nrf2-mediated gene expression and protection from superoxide-induced damage. Neuropharmacology 60: 343-353.

129. Wruck CJ, Gotz ME, Herdegen T, Varoga D, Brandenburg LO, et al. (2008) Kavalactones protect neural cells against amyloid beta peptide-induced neurotoxicity via extracellular signal-regulated kinase 1/2-dependent 
nuclear factor erythroid 2-related factor 2 activation. Mol Pharmacol 73: 1785-1795.

130. Zambrano S, Blanca AJ, Ruiz-Armenta MV, MiguelCarrasco JL, Revilla E, et al. (2013) The renoprotective effect of L-carnitine in hypertensive rats is mediated by modulation of oxidative stress-related gene expression. European Journal of Nutrition 52: 1649-1659.

131. Song SM, Park YS, Lee A, Cho YG, Kim DS, et al. (2009) [Concentrations of blood vitamin A, C, E, coenzyme Q10 and urine cotinine related to cigarette smoking exposure]. Korean J Lab Med 29: 10-16.

132. Galan P, Viteri FE, Bertrais S, Czernichow S, Faure H, et al. (2005) Serum concentrations of beta-carotene, vitamins $C$ and $E$, zinc and selenium are influenced by sex, age, diet, smoking status, alcohol consumption and corpulence in a general French adult population. Eur $\mathrm{J}$ Clin Nutr 59: 1181-1190.

133. Adhikari D, Baxi J, Risal S, Singh PP (2005) Oxidative stress and antioxidant status in cancer patients and healthy subjects, a case-control study. Nepal Med Coll J 7: $112-115$

134. Li W, Khor TO, Xu C, Shen G, Jeong WS, et al. (2008) Activation of Nrf2-antioxidant signaling attenuates NFkappaB-inflammatory response and elicits apoptosis. Biochem Pharmacol 76: 1485-1489.

135. Kim J, Cha YN, Surh YJ (2010) A protective role of nuclear factor-erythroid 2-related factor-2 (Nrf2) in inflammatory disorders. Mutat Res 690: 12-23.

136. Abate A, Yang G, Dennery PA, Oberle S, Schroder H (2000) Synergistic inhibition of cyclooxygenase-2 expression by vitamin $\mathrm{E}$ and aspirin. Free Radical Biology \& Medicine 29: 1135-1142.

137. Suzuki YJ, Aggarwal BB, Packer L (1992) Alpha-lipoic acid is a potent inhibitor of NF-kappa B activation in human $T$ cells. Biochem Biophys Res Commun 189: 1709-1715.

138. Honkura Y, Matsuo H, Murakami S, Sakiyama M, Mizutari K, et al. (2016) NRF2 Is a Key Target for Prevention of Noise-Induced Hearing Loss by Reducing Oxidative Damage of Cochlea. Sci Rep 6: 19329.

139. Kim SJ, Park C, Lee JN, Lim H, Hong GY, et al. (2015) Erdosteine protects $\mathrm{HEI}-\mathrm{OC} 1$ auditory cells from cisplatin toxicity through suppression of inflammatory cytokines and induction of Nrf2 target proteins. Toxicology and Applied Pharmacology 288: 192-202.

140. So H, Kim H, Kim Y, Kim E, Pae HO, et al. (2008) Evidence that cisplatin-induced auditory damage is attenuated by downregulation of pro-inflammatory cytokines via Nrf2/ HO-1. J Assoc Res Otolaryngol 9: 290-306.

141. Kim SJ, Park C, Han AL, Youn MJ, Lee JH, et al. (2009) Ebselen attenuates cisplatin-induced ROS generation through Nrf2 activation in auditory cells. Hear Res 251: 70-82.

142. Ma W, Hu J, Cheng Y, Wang J, Zhang X, et al. (2015) Ginkgolide $B$ protects against cisplatin-induced ototoxicity: enhancement of Akt-Nrf2-HO-1 signaling and reduction of NADPH oxidase. Cancer Chemother Pharmacol 75: 949959.

143. Choi BM, Chen XY, Gao SS, Zhu R, Kim BR (2011) Antiapoptotic effect of phloretin on cisplatin-induced apoptosis in HEI-OC1 auditory cells. Pharmacol Rep 63: 708-716.

144. Hoshino T, Tabuchi K, Nishimura B, Tanaka S, Nakayama $\mathrm{M}$, et al. (2011) Protective role of Nrf2 in age-related hearing loss and gentamicin ototoxicity. Biochemical and Biophysical Research Communications 415: 94-98.

145. Chang Y, Huang SK, Wang SJ (2012) Coenzyme Q10 inhibits the release of glutamate in rat cerebrocortical nerve terminals by suppression of voltage-dependent calcium influx and mitogen-activated protein kinase signaling pathway. J Agric Food Chem 60: 11909-11918.

146. Schubert D, Kimura H, Maher P (1992) Growth factors and vitamin $\mathrm{E}$ modify neuronal glutamate toxicity. Proc Natl Acad Sci U S A 89: 8264-8267.

147. Sandhu JK, Pandey S, Ribecco-Lutkiewicz M, Monette R, Borowy-Borowski H, et al. (2003) Molecular mechanisms of glutamate neurotoxicity in mixed cultures of NT2derived neurons and astrocytes: protective effects of coenzyme Q10. J Neurosci Res 72: 691-703.

148. Yang TT, Wang SJ (2009)Pyridoxine inhibits depolarizationevoked glutamate release in nerve terminals from rat cerebral cortex: a possible neuroprotective mechanism? J Pharmacol Exp Ther 331: 244-254.

149. Hung KL, Wang CC, Huang CY, Wang SJ (2009) Cyanocobalamin, vitamin B12, depresses glutamate release through inhibition of voltage-dependent $\mathrm{Ca} 2+$ influx in rat cerebrocortical nerve terminals (synaptosomes). Eur J Pharmacol 602: 230-237.

150. Prasad KN (2015) Etiology of Alzheimer's disease prevention and improved management by micronutrients. Boca Raton, FL: CRC Press. 